\title{
DETERMINASI PELATIHAN, MOTIVASI, GAJI, DAN KOMPENSASI UNTUK PRODUKSI (STUDI KASUS PADA CV ANUGRAH WALET INDONESIA)
}

\author{
Andika Arianto ${ }^{1}$, Abid Muhtarom ${ }^{2}$, Haris Bashory Ismail ${ }^{3}$, Ruswaji Ruswaji ${ }^{4}$, Henny \\ Mahmudah $^{5}$ \\ Fakultas Ekonomi, Program Studi Manajemen Universitas Islam Lamongan \\ e-mail: Andika.arianto99@gmail.com
}

\begin{abstract}
ABSTRAK
Studied, salary has a dominant influence on productivity in CV. Anugrah Walet Indonesia. Economic growth in Indonesia is very rapid and causes the competition of the market is getting tighter. This study aims to determine the determination of training, motivation, salary, and compensation for CV production. Anugrah Walet Indonesia.This research uses descriptive method, in qualitative form using Probability Sampling technique. The sample of this research is 40 employees. This research uses validity test, reability, classical assumption, multiple linear regression, coefficient of determination, $t$ test, and $\mathrm{f}$ test. This study uses EVIEWS 9 program. Partially there is significant influence between training, motivation, salary, and compensation to production at CV. Grace swallowed Indonesia. Simultaneously there is a significant influence between training, motivation, salary, and compensation on production in CV. Grace swallowed Indonesia. Among the 4 independent variables salary has a dominant influence on productivity on CV. Anugrah Walet Indonesia
\end{abstract}

Keywords: Training, Motivation, Salary, Compensation and Productivity.

\section{PENDAHULUAN}

Pertumbuhan ekonomi di Indonesia sangatlah pesat dan menyebabkan pesaingan pasar semakin ketat. Pada era modern saat ini hampir semua perusahaan bergerak dalam bidang industri berlomba-lomba dengan para pesaing agar perusahaan dapat menjual produk melebihi target, tepat waktu dan tepat jumlah. Menurut Kaswan (2011:2) Sumber daya manusia merupakan asset terpenting bagi perusahaan yang paling penting dikarenakan merupakan penggerak utama di dalam organisasi.Menurut Wangsi \& Rawi (2018), Fenomena ini bertentangan dengan perlindungan konsumen dalam ekonomi islam, yaitu tidak adanya kejelasan produk (label) yang menjadikan konsumen berada di pihak yang dirugikan. Karna pada hakikatnya Ekonomi Islam menjaga dan melindungi hak-hak konsumen dalam mengonsumsi suatu produk sehingga dapat turut membantu para pelaku usaha untuk lebih bertanggung jawab dalam 
Andika Arianto, ${ }^{1}$ Abid Muhtarom, ${ }^{2}$ Haris Bashory Ismail,${ }^{3}$ Ruswaji, ${ }^{4}$ Henny Mahmudah ${ }^{5}$

kegiatan berproduksi demi mewujudkan kegiatan perdagangan yang aman bagi kemaslahatan umat.Agar dapat bersaing dengan perusahaan di bidang industri yang sama perlu dilakukan pemilihan dan pelatihan yang efesien guna menjadikan sumber daya manusia (SDM) yang lebih bermutu, ulet dalam bekerja dan mampu memajukan perusahaan. Menurut Rawi (2017).,Motivasi merupakan hasrat didalam diri seseorang yang menyebabkan orang tersebut melakukan tindakan. Seseorang sering melakukan tindakan untuk suatu hal demi mencapai tujuan. Motivasi mempersoalkan bagaimana caranya mendorong gairah kerja bawahan, agar mereka mau bekerja keras dengan memberikan semua kemampuan dan keterampilannya untuk mewujudkan tujuan perusahaan. Motivasi sangat berguna dalam membangun kinerja dalam organisasi perusahaan walaupun karyawan tersebut tidak memiliki potensi kerja dengan baik. Menurut Salamah, (2009) motivasi bersal dari kata motif yang diartikan dengan istilah dorongan. Dorongan atau tenaga tersebut merupakan bergerak gerak jiwa jasmani untuk berbuat. Jadi motivasi adalah suatu penggerak manusia atau bertingkahlaku dan mempunyai tujuan tertentu.

Pemberian gaji akan berpengaruh terhadap produksi dikarenakan uang masih menjadi motivator yang kuat bagi karyawan. Maka oleh sebab itu diharapkan para perusahaaan memerhatikan mengenai gaji kepada tenaga kerja. Enggan memberikan gaji sesuai hasil tenaga yang di lakukan oleh karyawan maka timbul hubungan antara karyawan dengan pihak perusahaan dapat terjalin dengan baik. Menurut Dessler (2015:418) Kompensasi adalah segala bentuk bayaran yang diberikan kepada karyawan dan timbul dari hubungan mereka. Kompensasi sering juga disebut dengan bonus.

Menurut Yuniarsih dkk, (2009:156) produktivitas kerja adalah hasil kongkrit (produk) yang dihasilkan oleh individu ataupun kelompok selama satuan tertentu dalam suatu proses kerja. Semakin tinggi produk yang dihasilkan dalam waktu yang semakin singkat dapat dikatakan bahwa tingkat produktivitasnya mempunyai nilai yang cukup tinggi. 
Andika Arianto, ${ }^{1}$ Abid Muhtarom, ${ }^{2}$ Haris Bashory Ismail, ${ }^{3}$ Ruswaji, ${ }^{4}$ Henny Mahmudah ${ }^{5}$

Jumlah karyawan CV. Anugrah Walet Indonesia sebanyak 65 orang. Dalam 1 hari rata-rata seorang karyawan mampu membersikan sarang burung walet 90 gram. CV. Anugrah walet Indonesia mengharuskan pekerja baru melakukan pelatihan selama 3 bulan dikarenakan pelatihan ini memungkinkan pekerja bisa bekerja dengan baik tanpa kendala barang produksi yang salah sortiran. Teknical meeating setiap minggu dilakukan guna evaluasi pekerjaan selama 1 minggu dikarenakan situasi pasar selalu berubah-ubah. CV. Anugrah walet Indonesia menggunakan sistem gaji borongan dan juga mendapatkan kompensasi (bonus) setiap 3 bulan sekali sesuai tingginya permintaan pasar.

\section{METODE PENELITIAN}

Penelitian ini menggunakan metode deskriptif. Penelitian Menurut Cooper (2007:2) penelitian deskriptif adalah penelitian terhadap masalahmasalah berupa fakta-fakta saat ini dari suatu populasi yang meliputi kegiatan penelitian sikap atau pendapat terhadap individu, organisasi, keadaan, ataupun prosedur lainnya.

Menurut Carmines dkk, (2006:26) Penelitian kuantitatif adalah penelitian yang datanya dinyatakan dalam angka dan dianalisis dengan teknik statistik. Bentuk penelitian kualitatif menggunakan teknik Probability Sampling digunakan dalam penelitian dimaksudkan untuk menganalisa dan memperoleh gambaran tentang analisis Pelatihan, motivasi, gaji dan Kompensasi terhadap Produksi di CV. Anugrah Walet Indonesia. Perusahaan CV. Anugrah Walet Indonesia terletak di desa Ngemplak, Kecamatan Boureno, Kabupaten Bojonegoro.

Menurut Sangadji dkk, (2010 : 186) populasi adalah wilayah generalisasi yang terdiri atas: subyek atau obyek dengan kualitas dan karakteristik tertentu yang diterapkan oleh peneliti untuk di pelajari dan kemudian di tarik kesimpulan. Populasi dalam penelitian ini adalah seluruh karyawan CV. Anugrah Walet Indonesia sebanyak 65 orang.

Menurut Sangadji dkk, (2010:186) Sampel adalah bagian dari jumlah dari karakteristik yang dimiliki oleh populasi . pengambilan jumlah sampel 
Determinasi Pelatihan,Motivasi,Gaji..... Andika Arianto, ${ }^{1}$ Abid Muhtarom,${ }^{2}$ Haris Bashory Ismail, ${ }^{3}$ Ruswaji, ${ }^{4}$ Henny Mahmudah ${ }^{5}$

dari populasi memiliki aturan dan tekniknya. Dengan mengunakan teknik yang benar, sampel diharapkan mewakili populasi sehingga kesimpulan untuk sampel dapat di generalisasikan menjadi kesimpulan populasi.Sampel dalam penelitian ini yaitu karyawan yang bekerja dalam bidang produksi (pembersihan sarang burung, packing, operator produksi) sebanyak 40 orang.

Kuesioner penelitian ini menggunakan model skala likert. Menurut sugiyono (2011:93) skala likert digunakan untuk mengungkap sikap, pendapat, dan presepsi seorang atau kelompok orang tentang fenomena sosial. Dalam skala likert, variabel yang akan diukur menjadi indikator variabel. Kemudian indicator tersebut dijadikan sebagai titik tolak untuk menyusun item-item instrumen yang dapat berupa pernyataan atau pertanyaan. Pengujian ini menggunakan bantuan program EVIEWS 9. Teknik pengolahan data menggunakan : uji validitas, uji reliabilitas, uji asumsi klasik (uji multikolinieritas, uji heteroskedastisitas, dan uji normalitas), analisis regresi liner berganda, koefisien determinasi, dan uji hipotesis (Uji $t$ dan Uji $f$ ).

\section{HASIL PENELITIAN DAN PEMBAHASAN}

Uji validitas digunakan untuk mengukur sah atau valid tidaknya suatu kuisioner (Ghozali, 2015:53). Sugiyono (2012:172) menjelaskan bahwa suatu kuesioner dikatakan valid jika pertanyaan atau pernyataan dalam kuesioner tersebut mengungkapkan sesuatu yang akan diukur oleh kuesioner itu sendiri. berdasarkan data perhitungan Microsoft excel diketahui bahwa seluruh variabel bebas yaitu pelatihan, motivasi, gaji dan kompensasi lebih besar dari $\mathrm{R}$ tabel dengan signifikansi 5\% yaitu, 0,3120 maka semua instrumen dikatakan valid. 
Determinasi Pelatihan,Motivasi,Gaji..... Andika Arianto, ${ }^{1}$ Abid Muhtarom, ${ }^{2}$ Haris Bashory Ismail, ${ }^{3}$ Ruswaji, Henny Mahmudah ${ }^{5}$

\begin{tabular}{lcll}
\hline Pertanyaan & R hitung & R table & Keterangan \\
\hline X1.1 & 0.602856872 & 0,3120 & Valid \\
X1.2 & 0.369760955 & 0,3120 & Valid \\
X1.3 & 0.438866729 & 0,3120 & Valid \\
X2.1 & 0.591183848 & 0,3120 & Valid \\
X2.2 & 0.560004928 & 0,3120 & Valid \\
X2.3 & 0.520500523 & 0,3120 & Valid \\
X3.1 & 0.572875388 & 0,3120 & Valid \\
X3.2 & 0.356575668 & 0,3120 & Valid \\
X3.3 & 0.412159216 & 0,3120 & Valid \\
X3.4 & 0.433855347 & 0,3120 & Valid \\
X4.1 & 0.561618672 & 0,3120 & Valid \\
X4.2 & 0.637903334 & 0,3120 & Valid \\
X4.3 & 0.506060545 & 0,3120 & Valid \\
Y1.1 & 0.337408081 & 0,3120 & Valid \\
Y1.2 & 0.493268051 & 0,3120 & Valid \\
Y1.3 & 0.407435008 & 0,3120 & Valid \\
& Sumber: Microsoft Excel 2007
\end{tabular}

Berkaitan dengan reabilitas, diketahui dari hasilR hitung diatas Arikunto (2013:100) menyatakan bahwa reabilitas berhubungan dengan masalah kepercayaan. Suatu tes dapat dikatakan mempunyai taraf kepercayaan yang tinggi jika tes tersebut adalah 0.437377 dan $\mathrm{R}$ tabel 0,3120. Untuk uji reabilitas, hasil pengujian menunjukkan bahwa nilai $\mathrm{R}$ hitung $>\mathrm{R}$ tabel $=0.437377>0,3120$, maka dapat memberikan hasil yang tetap. Dapat

Tabel 5.3 Uji reabilitas

\begin{tabular}{|ll|}
\hline $\mathrm{R}$ hitung & $=0.437377$ \\
$\mathrm{R}$ tabel & $=0,3120$
\end{tabular}

Sumber: Microsoft Excel 2007

Menurut Gunawan (2016:92) uji asumsi klasik merupakan uji data yang digunakan untuk mengetahui apakah data penelitian memenuhi syarat untuk dianalisis lebih lanjut, guna menjawab hipotetis penelitian. Ghozali (2012:105) mengnyatakan uji multikorineritas bertujuan untuk menguji apakah model regresi ditemukan adanya korelasi antar variabel bebas (independen). Untuk 
Andika Arianto, ${ }^{1}$ Abid Muhtarom,${ }^{2}$ Haris Bashory Ismail, ${ }^{3}$ Ruswaji, ${ }^{4}$ Henny Mahmudah ${ }^{5}$

melihat apakah dalam model regresi terjadi multikorineritas, dapat dilihat melalui besarnya nilai VIF (Variance Inflation Factor). Jika nilai VIF melebihi angka 10, maka model regresi tersebut terjadi multikorineritas. Sehingga dapat disimpulkan bahwa nilai VIF pada variabel pelatihan $\left(\mathrm{X}_{1}\right)$, motivasi $\left(\mathrm{X}_{2}\right)$, gaji $\left(\mathrm{X}_{3}\right)$, dan kompensasi $\left(\mathrm{X}_{4}\right)$ kurang dari nilai kritis VIR sebesar 10 dan dalam model regresi dinyatakan bahwa tidak terjadi gejala multikorineritas.

Tabel 5.7Uji multikolineritas

Variance Inflation Factors

Date: 03/01/18 Time: 16:35

Sample: 140

Included observations: 40

\begin{tabular}{cccc}
\hline \hline Variable & $\begin{array}{c}\text { Coefficient } \\
\text { Variance }\end{array}$ & $\begin{array}{c}\text { Uncentered } \\
\text { VIF }\end{array}$ & $\begin{array}{c}\text { Centered } \\
\text { VIF }\end{array}$ \\
\hline \hline C & 0.8426 & 366.42 & NA \\
X1 & 0.0064 & 349.69 & 1.6665 \\
X2 & 0.0057 & 312.20 & 1.8499 \\
X3 & 0.0040 & 234.37 & 1.5053 \\
X4 & 0.0067 & 362.25 & 1.9662 \\
\hline \hline
\end{tabular}

Sumber:Output eviews 9

Ghozali (2012:139) mengatakan uji heterokeditas ini bertujuan menguji apakah dalam model regresi terjadi ketidaksamaan varian dari residual satu pengamatan ke pengamatan lain. .Untuk melihat terjadi atau tidaknya heteroskedastisitas dalam bentuk grafik yaitu jika residual bergerak konstan artinya tidak ada heteroskedastiditas dan jika membentuk suatu pola maka mengidikasi adanya heteroskedastisitas.

Gambar 5.1 Uji heteroskeditas 
Andika Arianto, ${ }^{1}$ Abid Muhtarom, ${ }^{2}$ Haris Bashory Ismail, ${ }^{3}$ Ruswaji, ${ }^{4}$ Henny Mahmudah ${ }^{5}$

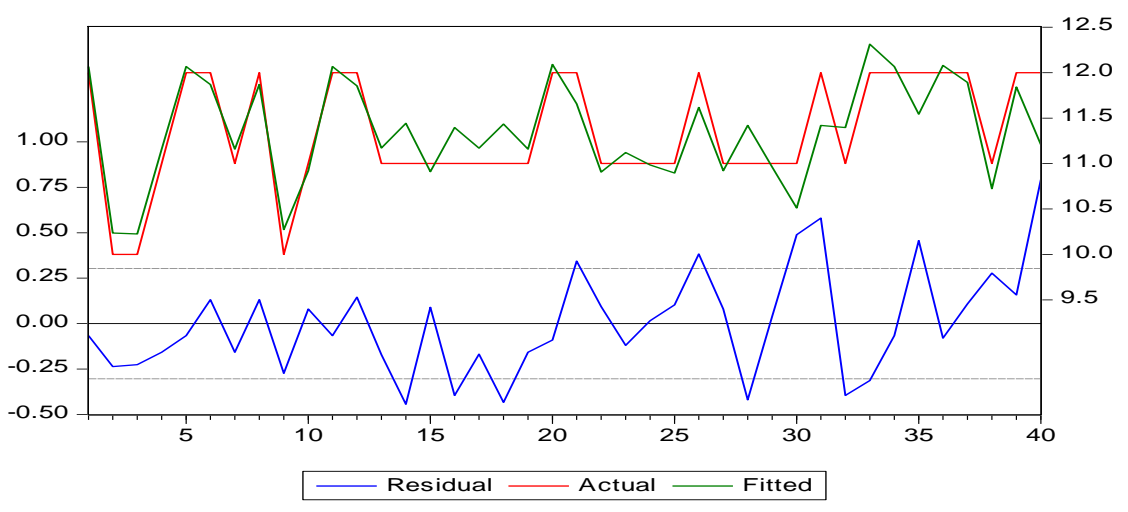

Sumber:Output eviews 9

Diatas terlihat bahwa grafik residual tidak membentuk suatu pola atau dengan kata lain residualnya cenderung konstan.

Menurut Ghozali (2012:160) mengungkapkan uji normalitas digunakan untuk menguji dalam model regresi variabel pengganggu atau residual memiliki distribusi normal.
Data yang baik dan layak dalam penelitian adalah yang memiliki distribusi normal. Pengujian ini dapat dikatakan normal dengan melihat hasil $p$ value (probability) > a. Pada tabel dibawah dapat disimpulkan bahwa hasil $p$ value (probability) > a $=0,25>0,05$, maka pengujian ini dapat dikatakan normal.

Gambar 5.2 Uji normalitas

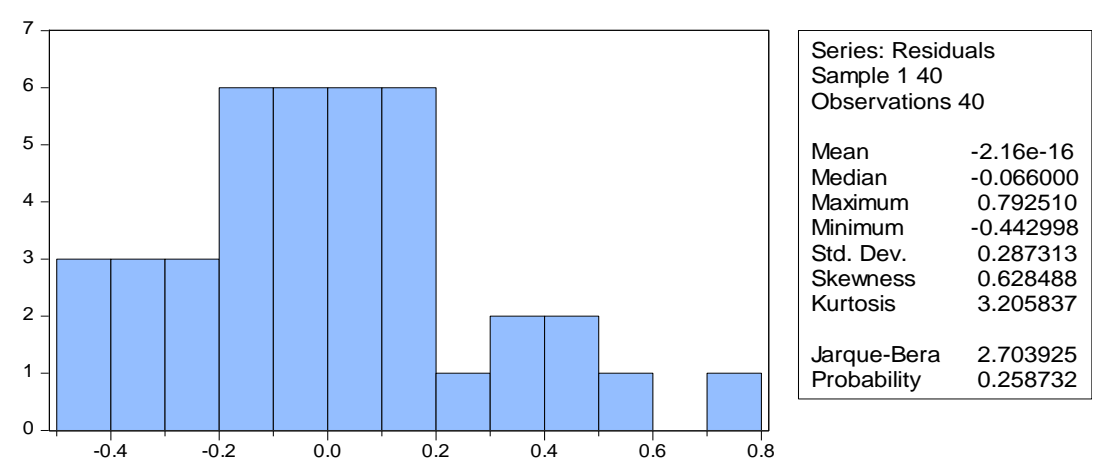

Sumber: Output eviews 9

disimpulkan bahwa variabel gaji $\left(\mathrm{X}_{3}\right)$ memiliki pengaruh yang lebih dominan terhadap produksi (Y) di CV. Anugrah Walet Indonesia.

$$
Y=a+\beta_{1} X_{1}+\beta_{2} X_{2}+\beta_{3} X_{3}+\beta_{4} X_{4}
$$


Determinasi Pelatihan,Motivasi,Gaji.....

Andika Arianto, ${ }^{1}$ Abid Muhtarom, ${ }^{2}$ Haris Bashory Ismail, ${ }^{3}$ Ruswaji, ${ }^{4}$ Henny Mahmudah ${ }^{5}$

$$
\begin{gathered}
Y=1.167412+0.197893 X_{1}+0.211605 X_{2} \\
+0.261310 X_{3}+0.237407 X_{4}
\end{gathered}
$$

Tabel 5.4 Uji regresi linier berganda

\begin{tabular}{lllll}
\hline $\begin{array}{l}\text { Dependent Variable: Y } \\
\text { Method: Least Squares } \\
\text { Date: 03/01/18 Time: 16:32 }\end{array}$ & & & \\
Sample: 140 & & & & \\
Included observations: 40 & & & \\
\hline \hline & & & & \\
Variable & Coefficient & Std. Error & t-Statistic & Prob. \\
\hline \hline & & & & \\
C & 1.167412 & 0.9179 & 1.2717 & 0.2118 \\
X1 & 0.197893 & 0.0805 & 2.4554 & 0.0192 \\
X2 & 0.211605 & 0.0755 & 2.7991 & 0.0083 \\
X3 & 0.261310 & 0.0639 & 4.0886 & 0.0002 \\
X4 & 0.237407 & 0.0821 & 2.8886 & 0.0066 \\
\hline \hline
\end{tabular}

Sumber: Output eviews 9

Hasil analisis regresi juga determinasi (R-squared) sebesar menunjukkan bahwa besarnya 0.786795 atau 78,6\%.

kontribusi variabel-variabel independen yaitu pelatihan $\left(\mathrm{X}_{1}\right)$, motivasi $\left(\mathrm{X}_{2}\right)$, gaji Besarnya variabel pelatihan $\left(\mathrm{X}_{1}\right)$, $\left(\mathrm{X}_{3}\right)$, dan kompensasi $\left(\mathrm{X}_{4}\right)$ terhadap motivasi $\left(\mathrm{X}_{2}\right)$, gaji $\left(\mathrm{X}_{3}\right)$, dan variabel dependen yaitu produktivitas kompensasi $\left(\mathrm{X}_{4}\right)$ terhadap produktivitas (Y) $78,6 \%$. Dan sisanya $21,4 \%$ (y), menunjukkan besarnya koefisien dipengaruhi oleh variabel yang tidak diteliti dalam penelitian ini.

Tabel 5.5 Koefisien determinasi

Dependent Variable: Y

Method: Least Squares

Date: 03/01/18 Time: 16:32

Sample: 140

\begin{tabular}{|c|c|c|c|}
\hline Variable & Coefficient & Std. Error t-Statistic & Prob. \\
\hline R-squared & 0.78679 & Mean dependent var & 11.350 \\
\hline Adjusted R-squared & 0.76242 & S.D. dependent var & 0.6222 \\
\hline S.E. of regression & 0.30328 & Akaike info criterion & 0.5681 \\
\hline Sum squared resid & 3.21940 & Schwarz criterion & 0.7793 \\
\hline Log likelihood & -6.36385 & Hannan-Quinn criter. & 0.6445 \\
\hline
\end{tabular}

Included observations: 40 
Andika Arianto, ${ }^{1}$ Abid Muhtarom, ${ }^{2}$ Haris Bashory Ismail, ${ }^{3}$ Ruswaji, ${ }^{4}$ Henny Mahmudah ${ }^{5}$

\begin{tabular}{llll} 
F-statistic & 32.2902 & Durbin-Watson stat & 1.4674 \\
Prob(F-statistic) & 0.00000 & \\
\hline \hline
\end{tabular}

\section{Sumber: output eviews 9}

Dalam hipotesis diduga bahwa pelatihan $\left(\mathrm{X}_{1}\right)$, motivasi $\left(\mathrm{X}_{2}\right)$, gaji $\left(\mathrm{X}_{3}\right)$ dan kompensasi $\left(\mathrm{X}_{4}\right)$ berpengaruh signifikan secara parsial terhadap produktivitas (Y) pada CV. Anugrah Walet Indonesia. Pengujian hipotesis dengan $\mathrm{a}=5 \%=0,05$, sedangkan derajat bebas pengujian ini adalah df $=$ $\mathrm{n}-\mathrm{k}=40-5=35$, maka dapat diketahui t tabel hipotesis pengujian ini adalah 2,030. Hasil analisis uji t dengan taraf signifikan 5\% sebagai berikut:

$\mathrm{H}_{0}$ : ditolak, tidak ada hubungan antara variabel pelatihan $\left(\mathrm{X}_{1}\right)$, motivasi $\left(\mathrm{X}_{2}\right)$, gaji $\left(\mathrm{X}_{3}\right)$, dan kompensasi $\left(\mathrm{X}_{4}\right)$ terhadap produktivitas $(\mathrm{Y})$.

$\mathrm{H}_{1}$ : diterima, ada hubungan antara variabel pelatihan $\left(\mathrm{X}_{1}\right)$, motivasi $\left(\mathrm{X}_{2}\right)$, gaji $\left(\mathrm{X}_{3}\right)$, dan kompensasi $\left(\mathrm{X}_{4}\right)$ terhadap produktivitas $(\mathrm{Y})$.

Tabel 5.6 Uji T

Dependent Variable: Y

Method: Least Squares

Date: 03/01/18 Time: 16:32

Sample: 140

Included observations: 40

\begin{tabular}{crrrr}
\hline \hline Variable & Coefficient & Std. Error & t-Statistic & Prob. \\
\hline \hline C & 1.16741 & 0.91794 & 1.27177 & 0.211 \\
X1 & 0.19789 & 0.08059 & 2.45542 & 0.019 \\
X2 & 0.21160 & 0.07559 & 2.79913 & 0.008 \\
X3 & 0.26131 & 0.06391 & 4.08865 & 0.000 \\
X4 & 0.23740 & 0.08218 & 2.88860 & 0.006 \\
\hline \hline
\end{tabular}

Sumber: output eviews 9

Berdasarkan hasil analisis uji t dapat disimpulkan bahwa pelatihan, motivasi, gaji dan kompensasi memiliki pengaruh signifikan secara parsial terhadap produksi, karena memiliki nilai signifikan $\mathrm{t}$ yang lebih kecil dari tingkat signifikan $5 \%$ atau memiliki nilai $\mathrm{t}_{\text {hitung }}$ $>\mathrm{t}_{\text {tabel. }}$

Dalam hipotesis diduga pelatihan, motivasi, gaji, dan kompensasi berpengaruh signifikan secara simultan terhadap produksi pada CV. Anugrah 
Determinasi Pelatihan,Motivasi,Gaji..... Andika Arianto, ${ }^{1}$ Abid Muhtarom,${ }^{2}$ Haris Bashory Ismail, ${ }^{3}$ Ruswaji, ${ }^{4}$ Henny Mahmudah ${ }^{5}$

Walet Indonesia. Untuk membuktikan hipotesis ini digunakan uji f, jika hasil statistik f pada taraf signifikan $a=5 \%$ diperoleh nilai signifikansi 0,05 atau nilai $\mathrm{f}_{\text {hitung }}>\mathrm{f}$ tabel berarti variabelvariabel bebas secara simultan mempunyai pengaruh yang signifikan terhadap variabel lain

Tabel 5.6 Uji F

Dependent Variable: Y

Method: Least Squares

Date: 03/01/18 Time: 16:32

Sample: 140

Included observations: 40

\begin{tabular}{lrll}
\hline \hline \multicolumn{1}{c}{ Variable } & Coefficient & \multicolumn{1}{c}{ Std. Error t-Statistic } & Prob. \\
\hline \hline R-squared & 0.78679 & Mean dependent var & 11.350 \\
Adjusted R-squared & 0.76242 & S.D. dependent var & 0.6222 \\
S.E. of regression & 0.30328 & Akaike info criterion & 0.5681 \\
Sum squared resid & 3.21940 & Schwarz criterion & 0.7793 \\
Log likelihood & -6.36385 & Hannan-Quinn criter. & 0.6445 \\
F-statistic & 32.2902 & Durbin-Watson stat & 1.4674 \\
Prob(F-statistic) & 0.00000 & & \\
\hline \hline
\end{tabular}

Sumber: output eviews 9

Didapat nilai $f$ hitung $=32.29026$ sedangkan untuk nilai $f_{\text {tabel }}$ dengan nilai tingkat kesalahan (a) sebesar 0,05 (5\%) dan derajat kebebasan (df) pembilang $=$ $\mathrm{k}=4$ sedangan derajat kebebasan (df) penyebut $=\mathrm{n}-\mathrm{k}-1=35$, maka didapat nilai $\mathrm{f}_{\text {tabel }}=\mathrm{f}_{0,050}(4)(35)=2,64$. Maka didapat $32.29026>2,64$. Artinya diperoleh asumsi bahwa $\mathrm{H}_{0}$ diterima, sehingga teruji bahwa variabel-variabel bebas yaitu pelatihan, motivasi, gaji, dan kompensasi berpengaruh signifikan secara simultan terhadap produksi.

\section{KESIMPULAN}

Dari hasil penelitianyang telah dilakukan, maka dapat ditarik kesimpulan sebagai berikut:

1. Secara parsial terdapat pengaruh yang signifikan antara pelatihan, motivasi, gaji, dan kompensasi terhadap produksi pada CV. Anugrah walet Indonesia.

2. Secara simultan terdapat pengaruh yang signifikan antara pelatihan, motivasi, gaji, dan kompensasi terhadap produksi pada CV. Anugrah walet Indonesia. 
Determinasi Pelatihan,Motivasi,Gaji.....

Andika Arianto, ${ }^{1}$ Abid Muhtarom, ${ }^{2}$ Haris Bashory Ismail, ${ }^{3}$ Ruswaji, ${ }^{4}$ Henny Mahmudah ${ }^{5}$

3. Diantara 4 variabel bebas yang diteliti, gaji memiliki pengaruh dominan terhadap produktivitas pada CV. Anugrah Walet Indonesia. Terbukti dengan membandingkan nilai beta $\beta$ dari hasil uji analisis regresi linier berganda.

\section{DAFTAR PUSTAKA}

Arikunto, dkk, 2013. Prosedur Penelitian Suatu Pendekatan Praktik. Jakarta : Rineka cipta.

Abdussamad, 2014. Pengaruh Kompensasi Terhadap Produktivitas Kerja Karyawan. Gorontalo: Universitas Negeri Gorontalo

Dessler, Gary, 2015. Manajemen Sumber Daya Manusia Edisi 14. Jakarta : Salemba Empat.

Ghozali, Imam, 2012. Aplikasi Analisis Multivariate dengan Program
IBM SPSS 2.0. Semarang : Universitas Diponegoro

Kaswan,2016. Pelatihan dan Pengembangan untuk Meningkatkan Kinerja SDM. Bandung : Alfabeta.

Rahmawati, 2013. Pengaruh Motivasi Terhadap Produktivitas kerja Karyawan. Tulungagung:

Univeritas Tulungagung.

Rawi, R. D. P. (2017). Analisis Hubungan Motivasi Terhadap Kinerja Pegawai (Studi Kasus Pada Kantor Kecamatan Ruing Kabupaten Ngada Ntt). Jurnal Noken: Ilmu-Ilmu Sosial, 2(2), 15-28.

Sugiyono, 2012. Metode Penelitian Bisnis. Bandung : Alfabeta niversitas Diponegoro

Wangsi, M. M., \& Rawi, R. D. P. (2018). Perlindungan Konsumen Dalam Pelabelan Produk Menurut Ekonomi Islam. Sentralisasi, 7(1), 1-9. 